\title{
Universiteit
}

Leiden

The Netherlands

\section{Anatomy of a notch: An in-depth experimental investigation and interpretation of combat traces on Bronze Age swords}

Gentile, V.; Gijn, A.L. van

\section{Citation}

Gentile, V., \& Gijn, A. L. van. (2019). Anatomy of a notch: An in-depth experimental investigation and interpretation of combat traces on Bronze Age swords. Journal of Archaeological Science, 105, 130-143. doi:10.1016/j.jas.2019.02.004

Version:

Publisher's Version

License:

Licensed under Article 25fa Copyright Act/Law (Amendment Taverne)

Downloaded from: https://hdl.handle.net/1887/81704

Note: To cite this publication please use the final published version (if applicable). 


\title{
Anatomy of a notch. An in-depth experimental investigation and interpretation of combat traces on Bronze Age swords
}

\author{
V. Gentile*, A. van Gijn \\ Leiden University, Faculty of Archaeology, Department of Archaeological Science, 2333 CC, Leiden, Netherlands
}

\section{A R T I C L E I N F O}

\section{Keywords:}

Experimental archaeology

Metalwork wear analysis

Use-wear analysis

Bronze Age

Weapons

Warfare

\begin{abstract}
A B S T R A C T
Weaponry is one of the most widespread categories of metalwork from the European Bronze Age. Different lines of evidence point out that violent encounters and martial values played a significant role both in communities' lives and ideologies. Hence, reconstructing the practices surrounding Bronze Age weaponry is pivotal for the understanding of many aspects of coeval societies. Nevertheless, the study of the functionality and use-life of such items has developed rather late compared to other categories of objects (e.g. flint implements). Currently, experimental archaeology and use-wear analysis concerning metalwork are facing the challenge of leaving the stage of 'infancy' to become fully developed fields of study. This paper aims at contributing to such a development by illustrating the potential and the results of an experimental framework for the investigation of combat with bronze weaponry (swords in this paper) which offers a viable compromise between actualism and variable control. We provide an in-depth account of the results by describing both the morphology and the formation mechanics of the features obtained supported by extensive photographic documentation. Furthermore, we discuss our observations regarding the relationship between specific combat movements and the type of marks produced on weapons. Finally, the results of a pilot use-wear study on Bronze Age swords are presented in order to assess the validity of our approach.
\end{abstract}

\section{Introduction}

Recent archaeological discoveries, such as the Tollense Valley battlefield (Jantzen et al., 2011; Lidke et al., 2018), provided unprecedented evidence for large-scale violent encounters in Bronze Age (BA) Europe (c. 2500-800 BC). However, martial expressions were not restricted to the battlefield alone: warriors and weaponry constitute one of the most frequent motifs in the figurative art of the time, and certain weapons -swords in particular- were often deposited in lavish burials or intentionally 'sacrificed' in natural places, such as rivers, all across the European continent (Bradley, 2017; Fontijn, 2005; Harrison, 2004; several chapters in Horn and Kristiansen, 2018a; Harding, 2007; Osgood et al., 2000). Consequently, many scholars agree that in this period martial practices also become institutionalized and contribute to the formation and maintenance of specific social organizations and roles (e.g. Harding, 2007; Harrison, 2004; Horn and Kristiansen, 2018b; Kristiansen and Larsson, 2005; Vandkilde, 2014, 2018).

The study of the ways and the contexts in which martiality was expressed in BA communities has, thus, wide relevance. Effectively reconstructing the events weapons have been through before they entered the archaeological record can enhance our understanding of the dynamic of interpersonal violence in the BA (e.g. Anderson, 2011; Horn, 2013; Kristiansen, 2002; Molloy, 2017; several chapters in Uckelmann and Modlinger, 2011), and provide indications on what influenced the choice of certain items for selective depositions (e.g. Bradley, 2017; Dolfini, 2011; Fontijn, 2005; Kristiansen, 2002; Melheim and Horn, 2014; Mörtz, 2013, 2018; Quilliec, 2008; York, 2002).

Through experimental tests with replicas of archaeological items, it is possible to gain insights into their functionality (Callahan, 1999; Mathieu, 2002; Outram, 2008). Furthermore, by comparing traces produced on replicas by controlled activities, one can attempt the interpretation of traces detected on homologous archaeological tools (use-wear analysis) and glimpse at an object's life history (a.o. van Gijn, 2010; Marreiros et al., 2015). Until recently, bronze objects -weapons included- have been mainly the object of typological analyses (cf. the Prähistorische Bronzefunde series) and thoughts on their use were for a long time constructed on theoretical considerations built upon their morphology (Gutiérrez Sáez and Martín Lerma, 2015, 171; Roberts and Ottaway, 2003, 119). As a result, the study of use-wear on copper-alloy tools and weapons has only recently started and experimental programs are scant (Gutiérrez Sáez and Martín Lerma, 2015; Dolfini and Crellin, 2016; Horn and von Holstein, 2017, 98). The aim of this paper is

\footnotetext{
* Corresponding author.

E-mail address: v.gentile@arch.leidenuniv.nl (V. Gentile).
} 
contributing to the understanding of weapon use by presenting a systematic and replicable methodological framework for experimental combat with bronze swords, and an in-depth discussion of the traces produced.

In order to be scientifically valid and effectively replicable, an experiment must be based on the strict control of the variables involved (Mathieu, 2002; Lammers-Keijsers, 2005; Callahan, 1999). For this reason, meticulous lab tests -which employ controlled environments and analytical facilities- are often used in experimental archaeology. However, a gap exists between the laboratory experiment and how the proper action/processes took place in the past, with limited technology and little control over variables (Outram, 2008). Another way to perform experiments is by attempting to reproduce the process in its original context ('actualistic' experiments), aiming at a stronger analogy with what might have happened in the past, but at the expense of a considerable amount of control (Schenck, 2011, 87-8). The control-vsactualism debate -which often overlaps the difference between 'lab experiments' and 'field experiments'- is still a matter of discussion within the field of experimental archaeology (Schenck, 2011, 88; cf. various chapters in Ferguson, 2010). Which approach to implement is mostly dictated by the research questions. However, in most cases it is advisable to employ a mixed approach: for example, agreeing on a restricted amount of variables to keep under control during field tests, even at the expense of a certain degree of actualism (Schenck, 2011, 912).

The tension between actualism and control is also identifiable in the few experimental programs with copper-alloy tools, and is particularly evident for those concerning weaponry (Crellin et al., 2018, 286-290; see Dolfini and Crellin, 2016 for a review). Some studies aimed at reproducing traces on archaeological weapons by attaching replicas of copper-alloy blade edges to a rig and making them collide, with specific power and specific angles, against various types of surfaces (e.g. Bridgford, 2000; O'Flaherty et al., 2011). Other scholars focused on a more 'experiential' (Molloy, 2008, 117-118) appraisal of BA weapon's functionality through staged combat and cutting tests with replicas directly performed by humans (e.g. Anderson, 2011; Molloy, 2007, 2008, 2010).

Despite these pioneering works, the state of experimental and usewear studies on metalwork was recently still described as follows: "The experimental corpus is scarce; experimentation often lack structured designs. In addition, the definition and typification of marks is insufficient and there is a lack of relationship between the marks and the use variables." (Gutiérrez Sáez and Martín Lerma, 2015, 185).

This paper takes on the latest calls for improvement (Dolfini and Crellin, 2016), and aims at offering a contribution to the discipline of experimental archaeology and use-wear analysis on bronze weaponry by:

- Presenting in detail an efficient and repeatable framework for combat experiments which offers an acceptable compromise between actualism and variable control.

- Adding to the current knowledge by testing a sword type and an alloy never tested before (see below).
- Providing an in-depth study and description of the wear marks produced, with the employment of stereo-microscopy (up to x60 magnification).

- Investigating the relation between gesture and the trace produced.

- Improving and expanding the reference collection for combat marks currently available.

Our combat tests with BA swords intend to address two main research questions:

What kind of traces does combat action leave on bronze swords? And to what extent are the traces produced influenced by the combat movement performed?

The knowledge obtained is subsequently applied to the micro-wear analysis of a sample of archaeological swords to test the validity of the methodology.

\section{Materials and methods}

Our specific research questions call for a hybrid experimental approach. Whereas the reproduction of 'actual' combat situation is essential to answer the first question, the second question requires an accurate monitoring of the action and a rigorous control over the variables involved. In order to do so, we conceived of a structured methodology departing from the suggestions of Kienlin and Ottaway (1998; further expanded in Roberts and Ottaway, 2003). Our experiments took place between the winter of 2015 and the spring of 2016 at the Faculty of Archaeology of Leiden University (see also Gentile, 2017). In the following paragraphs, we describe in detail the variables and outline our investigative framework.

\subsection{Weapons}

In order to restrict the variables to control, the experiments focused on one type of weapon only. Four replicas of the Gündlingen type swords (Fig. 1) were produced by the experienced smith Jeroen Zuiderwijk, using one of the archaeological Gündlingen swords stored in the National Museum of Antiquities in Leiden as a reference (n. k1896/ 9.1).

The Gündlingen sword-type dates to the Late BA (LBA; c. $1200-800$ BC) and probably represents a development of the British Ewart Park/ Thames type swords (Gerloff, 2004, 141-5; Warmenbol, 1988, 244-7). It constitutes one of the last advancements in BA weapon technology and seems designed for both thrusting and cutting motions (Molloy, 2017, 196-197). This type is widely distributed across North-Western Europe and the British Isles, both in burials and river contexts (Colquhoun and Burgess, 1988; Cowen, 1968; Gerloff, 2004, Fig. 17.8; Van der Vaart-Verschoof, 2017). Despite their representativeness for BA weapon development, Gündlingen swords have never been objects of tests before.

For the production of the replicas, an alloy consisting of c. $85 \% \mathrm{Cu}$, $12 \% \mathrm{Sn}, 3 \% \mathrm{~Pb}$ was used. Such a composition differs from the alloys tested in previous experiments with BA weapons (e.g. $90 \% \mathrm{Cu}, 9 \% \mathrm{Sn}$, $1 \% \mathrm{~Pb}$ in Anderson, 2011; 88\% Cu, 12\% Sn in Crellin et al., 2018 and

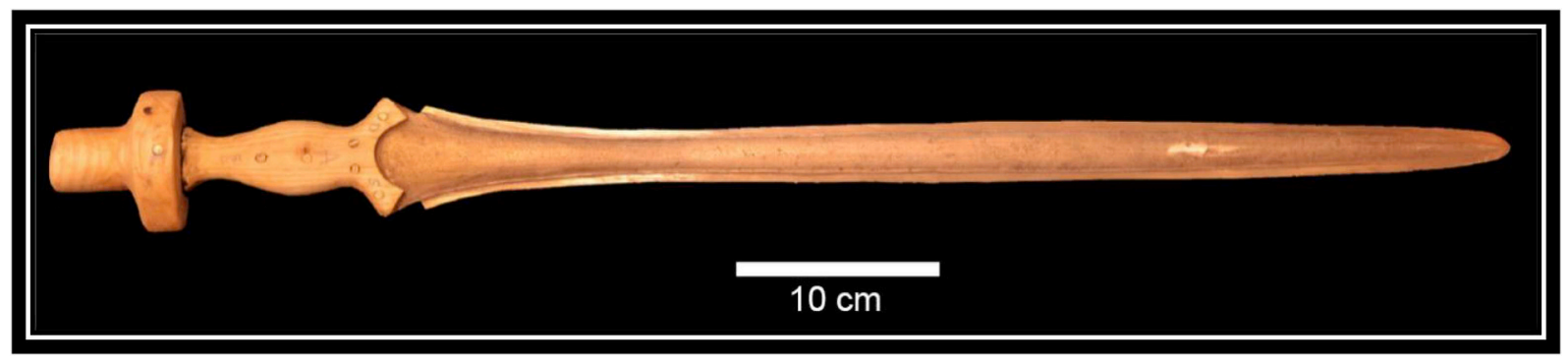

Fig. 1. One of the replicas used for the experiments. 
Herman et al. in press; $98 \% \mathrm{Cu}, 2 \%$ As in O'Flaherty et al., 2011). While the 'optimal' ratio for the alloying of bronze would be roughly one part of tin for every nine parts of copper, the presence of lead in LBA metalwork is not uncommon (cf. Arnoldussen and Visser, 2014; Huth, 2000; Radivojević et al., 2018). Although some LBA swords seem to have been cast following fixed recipes with no or little lead, perhaps to assure optimal structural properties (e.g. Jung and Mehofer, 2013), swords made of lead-rich -possibly recycled- metal are also well documented (Brandherm and Moskal-del Hoyo, 2010; Coffyn et al., 1981; Bray, 2016; Northover and Bridgeford, 2002). Soriano-Llopis and Gutiérrez-Sáez (2009) demonstrated that differences in the composition -namely the tin percentage- of an object can influence quantitatively, and to a lesser extent qualitatively, the formation of use-wear on copper-alloys objects. However, the impact of lead quantity on the development of damage features has yet to be established.

The replicas were cast in sand (as in Anderson, 2011) and their edges were hammered and sharpened to replicate BA sword edges. The handles and the pommels were constructed from ash wood and fixed with bronze rivets. At the end of the crafting process, the four specimens had a blade length ranging between 57.3 and $64 \mathrm{~cm}$ and a weight between $802 \mathrm{~g}$ and $870 \mathrm{~g}$ (with the weight variation mostly ascribable to differences in the pommel size).

\subsection{Fighters}

The combat experiments were performed by two experts with over a decade-long experience in ancient, medieval, and renaissance sword fighting. Fighter A is a 22 years old male, right-handed, $189 \mathrm{~cm}$ height, $85 \mathrm{~kg}$ weight, with a right arm length (from armpit to wrist) of $65 \mathrm{~cm}$. Fighter B is a 35 years old male, right-handed, $175 \mathrm{~cm}$ height, $80 \mathrm{~kg}$ weight, with a right arm length (from armpit to wrist) of $62 \mathrm{~cm}$. Such collaboration is crucial for the outcome of this paper for numerous reasons. Firstly, it complies with one of the basic principles of experimental archaeology of not making the learning process of a new skill affect the test (Callahan, 1999, 5). Secondly, a continuous discussion with the fighters was fundamental to the design of the single combat situations reproduced (see section 2.3). Furthermore, their feedback -recorded during and after the tests- constitutes a complementary source of insights alongside the experiment's results.

\subsection{Combat movements}

Seven different kinds of combat situations were designed to simulate plausible conditions of a fight between two right-handed opponents (Table 1). Shields -both in bronze and in perishable materials- were undoubtedly part of the LBA combat system (cf. Osgood et al., 2000; Molloy, 2009; Uckelmann, 2011). However, experimental trials suggest

Table 1

Description of the combat combinations performed in the experiments.

\begin{tabular}{|c|c|}
\hline combination & Description \\
\hline 1 & Slashing attack to the head, with the sword edge oriented roughly at a $90^{\circ}$ to the ground, opposed by a hard block. \\
\hline 2 & Slashing attack towards the upper body, with the edge of the sword oriented roughly at a $45^{\circ}$ to the ground, opposed by a hard block. \\
\hline 3 & Similar to N.2 but the defender, through a further rotation of the wrist, meets the incoming blow with the flat of his weapon rather than with the edge. \\
\hline 4 & Thrusting attack towards the upper body opposed by a hard block. \\
\hline 5 & Slashing attack towards the upper body, with the edge of the sword oriented roughly at a $45^{\circ}$ to the ground, opposed by a deflection. \\
\hline 6 & Thrusting attack towards the upper body opposed by a deflection. \\
\hline 7 & Similar to N. 5 but the defender, through a further rotation of the wrist, meets the incoming blow with the flat of his weapon rather than with the edge. \\
\hline 8 & Repetition of combination n. 4 \\
\hline
\end{tabular}

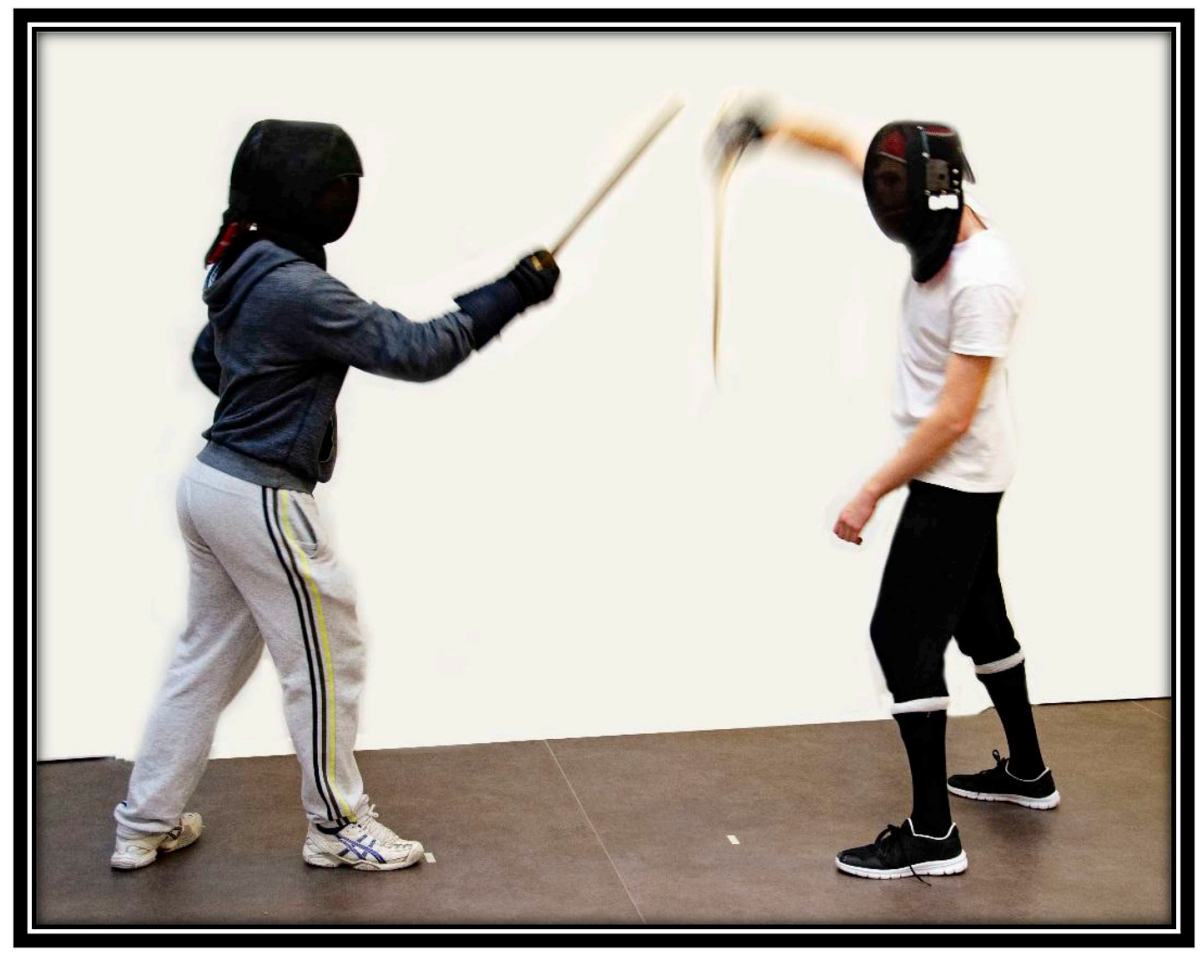

Fig. 2. Fighter B (left) performing a slashing attack while Fighter A (right) prepares a deflection. 


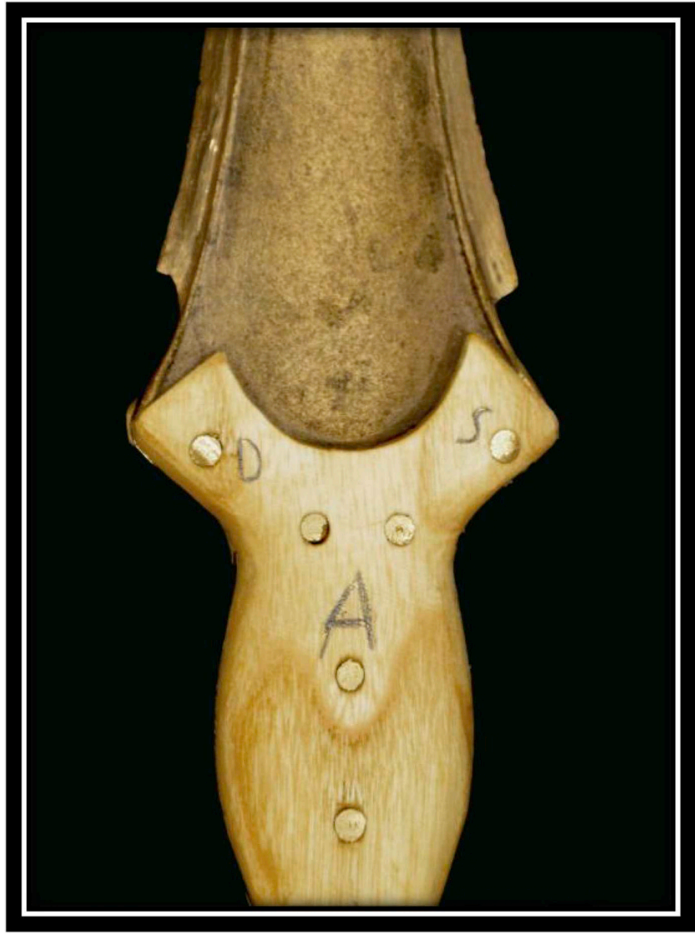

Fig. 3. Detail of the hilt of one of the replicas with indications for the fighters.

that only impacts with metal shields are capable of leaving clear marks on the edge of the weapons (Anderson, 2011, 606), and there is no evidence for bronze shields from the region where the archaeological swords selected for our use-wear analysis come from (southern Netherlands, see section 5). For these reasons, and in order to maximize the chances to create traces on the swords and reduce the number of variables to keep into account, our experiments focused on recreating sword-versus-swords impact situations.

To ensure proper documentation and variable control, it was necessary to break down a fluid and continuous combat activity into different units. Consequently, ancient fencing techniques have been reduced to essential combinations of attack and defence, performable with weapons with a size range similar to that of the Gündlingen swords. We chose the techniques of the 15th century German school of fencing with lange Messer (e.g. Lecküchner and Forgeng, 2015; Talhoffer and Hergsell, 1998), a cut-and-thrust sword c. $1 \mathrm{~m}$ long, as our main source of inspiration. We are aware however, that applying ancient fencing techniques, devised for steel weapons and conceived in different socio-cultural contexts, to BA combat is problematic and requires caution. Having this in mind, but in the absence of precise indications on BA martial arts, the basic notions of historical sword-fighting have been used exclusively as a bio-mechanical scaffolding for the conception of these tests. In accordance with the fighting experts (see section 2.2 ), we isolated the most elementary units of attack-and-defence, as much as possible devoid of any 'school-specific' precepts (cf. Table 1). It follows that the comparison of the marks produced experimentally with those detected on archaeological weaponry represents also a tool for evaluating the appropriateness of such an approach.

The attack movements devised were condensed into three main strikes: one thrusting attack, and two cutting attacks at different angles. Other angles of attack have not been tested in order to limit the variables to control and because they are assumed to make the weapons collide in a similar fashion to the angles tested (e.g. an angle of attack of $135^{\circ}$ is expected to result in a collision similar - but mirrored-to the one produced by a $45^{\circ}$ attack). For each attacking movement, two defensive

Table 2

Synoptic table of the results of the experiments grouped by 'scenario' (two repetitions of the same combat combination; see section 3).

\begin{tabular}{|c|c|c|c|c|c|c|c|c|c|c|c|c|}
\hline & Scenario & (A)ttack/(D)efense & Notches & Dents & Chipping & Rippling & Bowing & Flattening & Grazing & Blow mark & Bending & Structural failure \\
\hline \multirow[t]{16}{*}{ Hard blocks } & \multirow[t]{4}{*}{1} & A & $\mathrm{X}$ & - & - & - & - & - & - & - & - & - \\
\hline & & $\mathrm{D}$ & $\mathrm{X}$ & $\mathrm{X}$ & - & $\mathrm{X}$ & - & - & - & - & - & - \\
\hline & & A & $\mathrm{X}$ & - & - & - & - & - & - & - & - & - \\
\hline & & $\mathrm{D}$ & - & $\mathrm{X}$ & - & - & - & - & - & - & - & - \\
\hline & \multirow[t]{4}{*}{2} & A & $\mathrm{X}$ & - & - & - & - & - & - & - & - & - \\
\hline & & $\mathrm{D}$ & $\mathrm{X}$ & - & - & - & - & - & - & - & - & - \\
\hline & & A & $\mathrm{X}$ & - & - & - & - & - & - & - & - & - \\
\hline & & $\mathrm{D}$ & $\mathrm{X}$ & - & - & - & - & - & - & - & - & - \\
\hline & \multirow[t]{4}{*}{3} & A & - & - & - & - & - & $\mathrm{X}$ & - & - & - & - \\
\hline & & $\mathrm{D}$ & - & - & - & - & - & - & - & $\mathrm{X}$ & $\mathrm{X}$ & - \\
\hline & & A & - & - & - & - & - & $\mathrm{X}$ & - & - & - & - \\
\hline & & D & - & - & - & - & - & - & - & - & - & - \\
\hline & \multirow[t]{4}{*}{4} & A & $\mathrm{X}$ & - & - & - & $X$ & - & - & - & - & - \\
\hline & & $\mathrm{D}$ & - & $X$ & - & - & - & - & - & - & - & - \\
\hline & & A & $\mathrm{X}$ & $X$ & - & - & - & - & - & - & - & - \\
\hline & & D & $\mathrm{X}$ & - & - & - & - & - & - & - & - & - \\
\hline \multirow[t]{12}{*}{ Deflections } & \multirow[t]{4}{*}{5} & A & - & - & - & - & - & $\mathrm{X}$ & - & - & - & - \\
\hline & & $\mathrm{D}$ & - & - & - & - & - & - & $X$ & - & - & - \\
\hline & & A & - & $\mathrm{X}$ & - & - & - & - & - & - & - & - \\
\hline & & $\mathrm{D}$ & $\mathrm{X}$ & - & - & - & - & - & - & - & - & - \\
\hline & \multirow[t]{4}{*}{6} & A & - & $X$ & $\mathrm{X}$ & - & - & - & - & - & - & - \\
\hline & & $\mathrm{D}$ & - & $X$ & - & - & - & - & - & - & - & - \\
\hline & & A & - & - & - & $\mathrm{X}$ & - & - & - & - & - & - \\
\hline & & D & $\mathrm{X}$ & - & - & - & - & - & - & - & - & - \\
\hline & \multirow[t]{4}{*}{7} & A & - & - & - & - & - & $\mathrm{X}$ & - & - & - & $\mathrm{X}$ \\
\hline & & $\mathrm{D}$ & - & - & - & - & - & - & $\mathrm{X}$ & $\mathrm{X}$ & - & - \\
\hline & & A & - & - & - & - & - & $\mathrm{X}$ & - & - & - & - \\
\hline & & $\mathrm{D}$ & - & - & - & - & - & - & $X$ & - & $\mathrm{X}$ & - \\
\hline \multirow[t]{4}{*}{ Hard blocks } & \multirow[t]{4}{*}{8} & A & $\mathrm{X}$ & - & - & - & - & - & - & - & - & - \\
\hline & & $\mathrm{D}$ & - & $\mathrm{X}$ & - & - & - & - & - & - & - & - \\
\hline & & A & - & $\mathrm{X}$ & - & - & - & - & - & - & - & - \\
\hline & & $\mathrm{D}$ & $\mathrm{X}$ & - & - & - & - & - & - & - & - & - \\
\hline
\end{tabular}




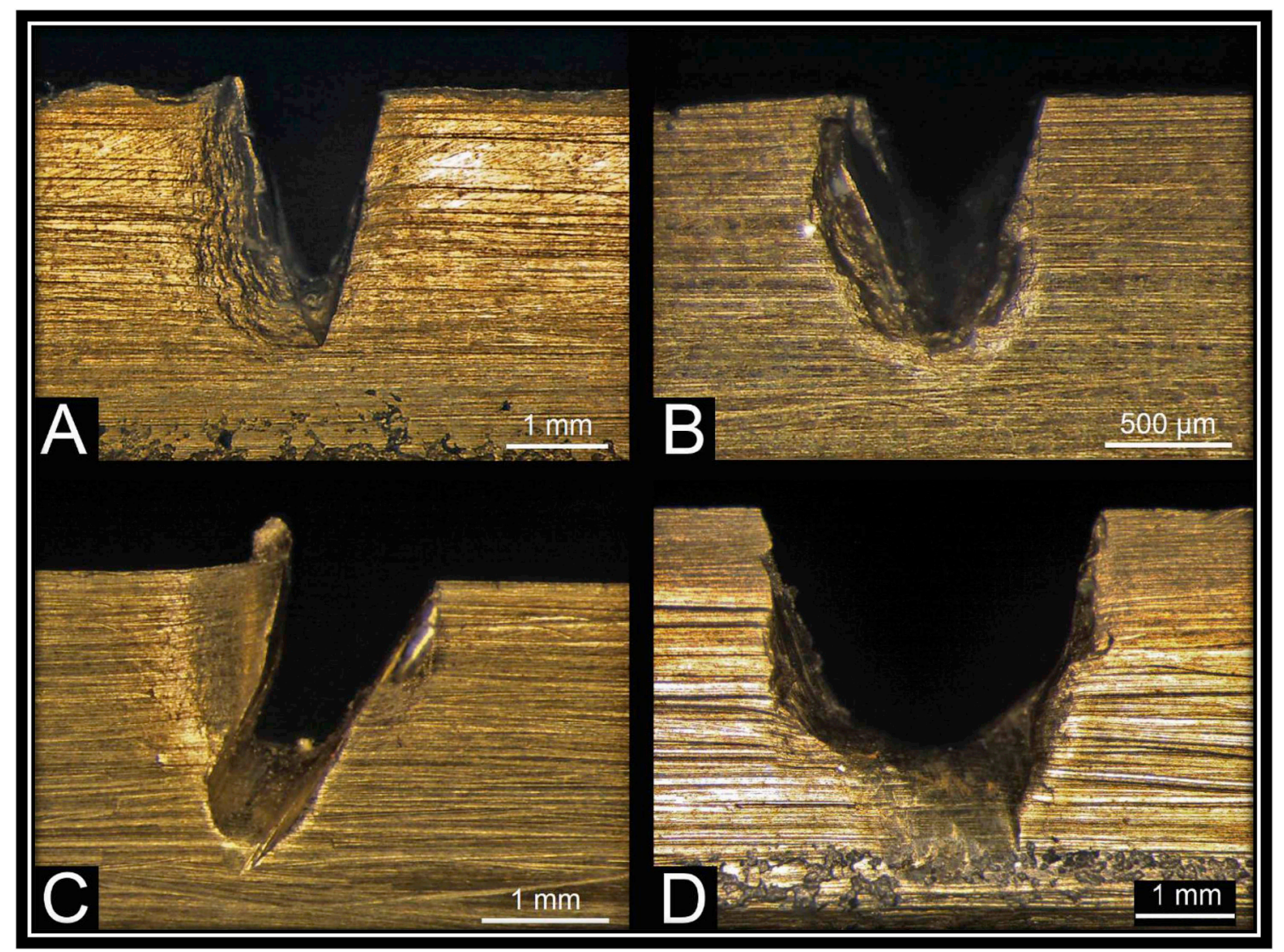

Fig. 4. Examples of traces obtained experimentally. (A, B) V-shaped vertical notches; (C) U-shaped curved notch; (D) U-shaped vertical notch.

approaches have been tested. One type of defence consisted of basic 'hard blocks', while the other envisaged more advanced 'deflections' (Table 1). It has to be remarked that, contrary to 'static' blocks used in other research (e.g. Anderson, 2011; Crellin et al., 2018), both the hard blocks and the advanced deflections implemented in this study aim at mimicking actual combat situations in which the defending weapons are also in motion. The first could be defined as intercepting and pushing the enemy sword away opposing considerable strength to the enemy's blow. This is deemed the safest and most instinctive way to respond to an attack and it is usually the first type of defence learned by sword-fighting novices. The second defensive style envisages less violent impacts and aims mostly at redirecting the opponent's blow making use of its own momentum. Effective deflections have more chance to leave the attacker uncovered and can use the momentum gained to turn fluidly into a counterattack (Fig. 2). However, they also require a higher level of training to be mastered. In order to test different ways of defending, parrying with the flat of the weapon was also tested. For the sake of control and accurate documentation, only 'first encounter' impacts have been tested, while movements developing from previous blows (e.g. a counterattack after a deflection and the possible response to it) were left out of the experimental protocols. All the movements have been performed with the swords held in a 'hammer-grip' (cf. Molloy, 2008).

\section{Experiment design}

To reduce the ambiguity around the origin of the traces, each replica was documented by stereomicroscope (Leica M80, up to x60 magnification) before conducting the experiments. Furthermore, each sword was ideally divided into four regions, two sides (A and B) and two edges ( $S$ and $\mathrm{D}$ ). The edge $\mathrm{S}$ (strike) was used in attacking movements only, while the edge $\mathrm{D}$ (defence) was restricted to defending movements, and defenses with the flat were operated with side B (Fig. 3). As a result of this strategy, each region of each sword would bear 'attacking' or 'defending' marks only, facilitating the comparison between the traces produced by these two types of movements.

In order to assess the degree of the uniformity of the results, each combination has been repeated twice, with the fighters taking turns in attacking and defending. A set of two repetitions of the same combination forms a test 'scenario'. The scenario involving a hard block against a thrusting attack was deemed by the fighters to be the most dangerous for the swords' integrity and expected to likely bend one of the swords: it was thus performed twice (a total of four combinations) in order to test the resistance of the weapons to the extreme (Table 1).

The fighters practiced with wooden 'wasters' before performing each combat scenario with the bronze replicas. After every combination, the traces produced were noted, sketched on a pre-made 1:1 drawing of the replicas, and photographed. Fighter's comments were also noted on the spot. Subsequently, the fighters switched role and edge of the weapon to use (see above), and executed the next combination. After testing a scenario completely, dental casts of the traces were taken in order to minimize the loss of information in case the following impacts would have modified the traces previously produced. To achieve a better control and understanding of the dynamics involved in fighting with bronze swords, the tests have also been video recorded with a high FPS camera (GoPro) which allowed the observation of the impacts in slow-motion. At the end of the experiments the replicas have been studied under the stereomicroscope. Microscopic pictures of the damage features produced have been taken both from the side and from the top in order to properly document and interpret the micro- 


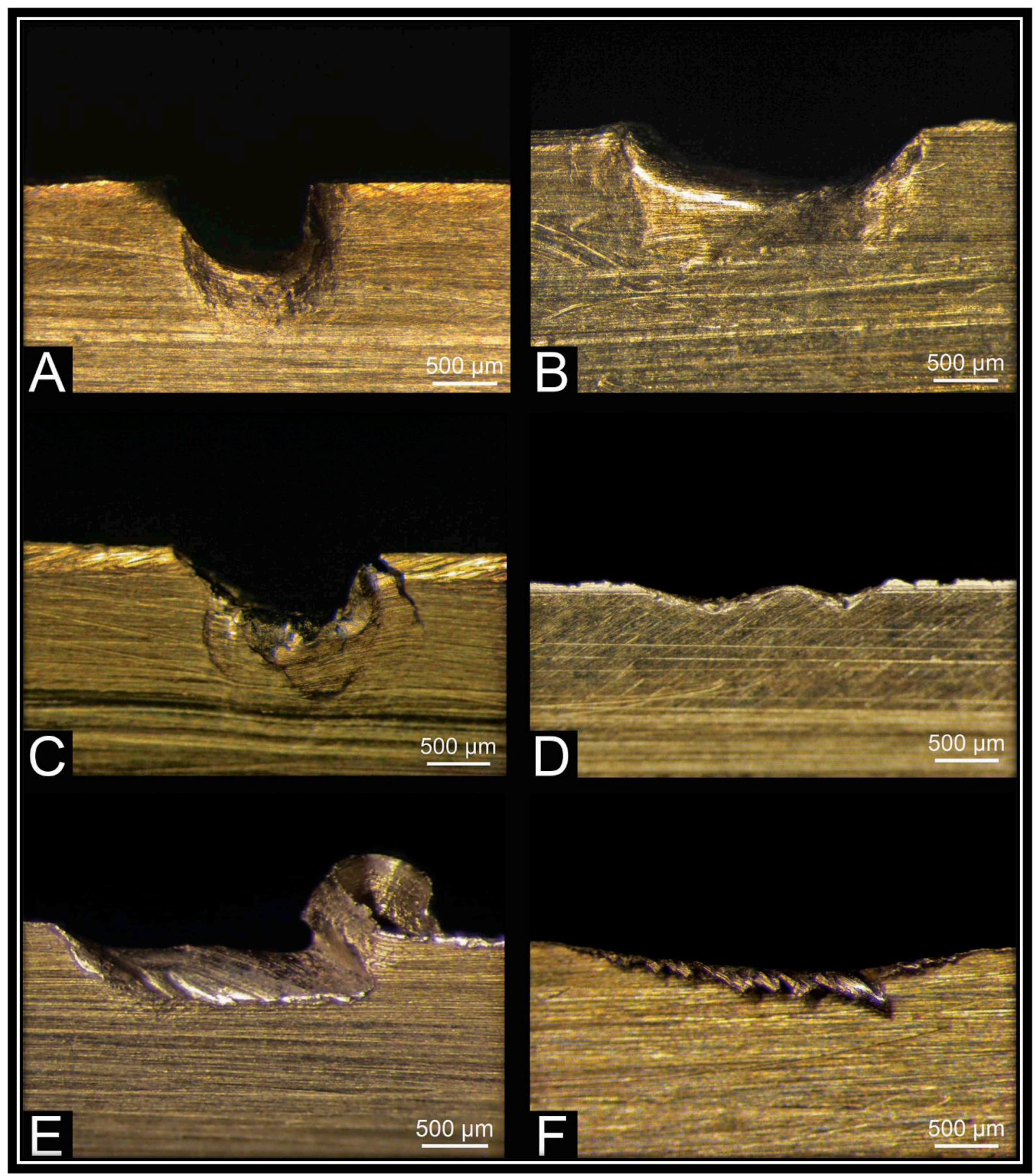

Fig. 5. Examples of traces obtained experimentally. (A) Asymmetrical dent; (B) symmetrical dent; (C) asymmetrical dent with thickening and fissures; (D) rippling; (E) chipping; (F) bowing.

morphological characteristic of each trace.

\section{Results}

In this section, general comments on the experiments' outcome are reported, followed by an in-depth description of the morphology and formation of each kind of combat trace produced. After each one of the 16 combinations tested (Table 2), at least one of the swords involved showed traces of damage. During the execution of the first tests, the fighters immediately reported the tendency of bronze replicas to 'ricochet' after the first impact, to an extent much higher than steel swords. This unexpected feature found further confirmation in the analysis of the footage from the slow-motion camera. As a result of this behaviour, one single encounter of the blades can produce several traces on the weapons, since the 'ricochet' of the primary impact might make the swords collide again before stopping. To some extent, similar dynamics have also been recently observed by Herman et al. (in press). No wrist-strain or any other kind of joint pain was reported by the fighters during the experiments, even when testing defending movements with the flat of the weapon (which requires substantial torsion of 


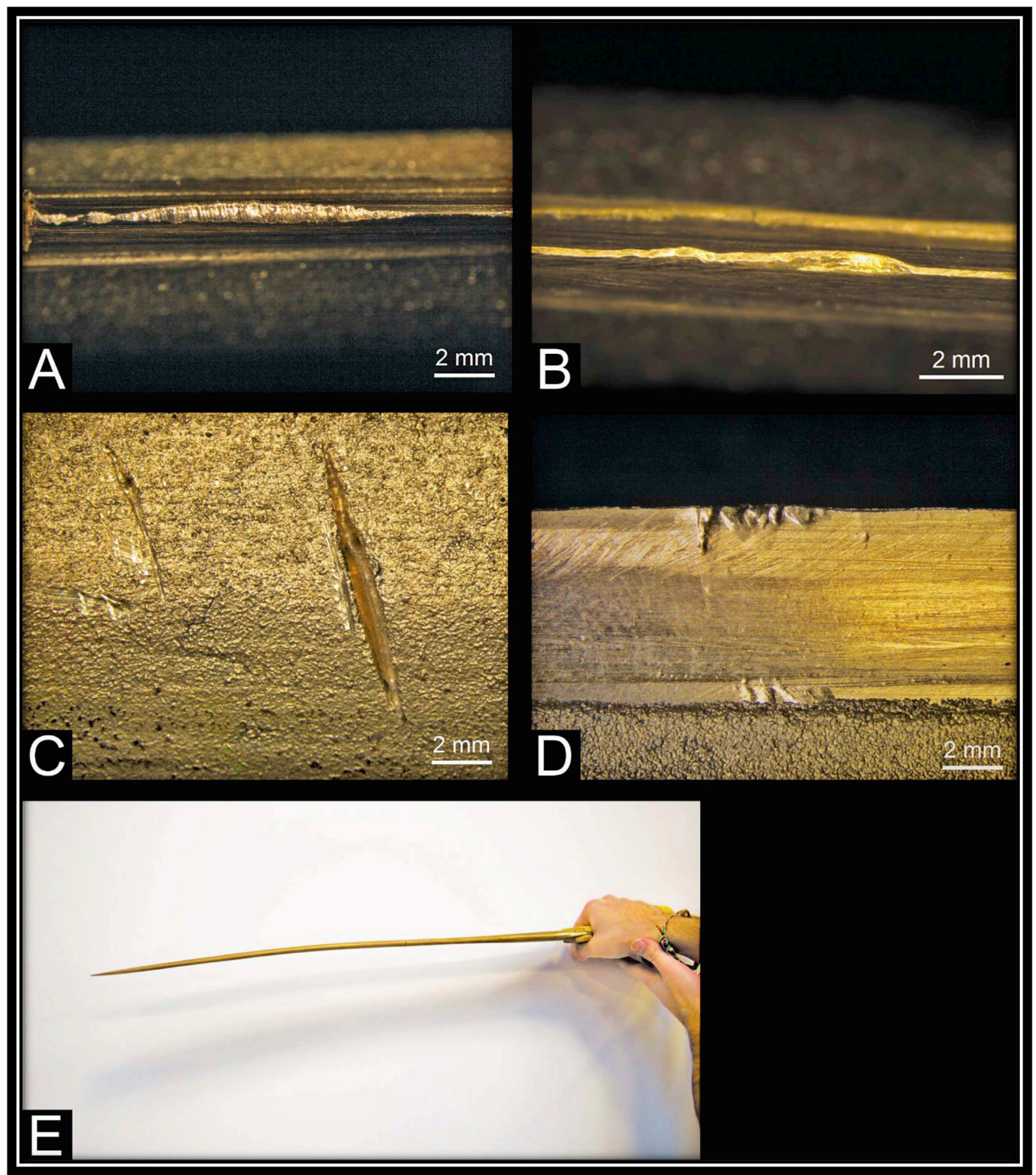

Fig. 6. Examples of traces obtained experimentally. (A, B) Flattening traces (top view); (C) blow marks; (D) grazing; (E) bending.

the wrist). Interestingly, this aspect is at odds with what recorded in other combat experiments (cf. Hermann et al. in press).

The tests produced an array of different features, and various formation micro-dynamics have been observed. Unfortunately, at the current stage of use-wear studies on copper-alloy objects, there is no well-established and unambiguous terminology to indicate the various traces recognized (Dolfini and Crellin, 2016; Gutiérrez Sáez and Martín Lerma, 2015). Furthermore, some characteristics of the experimental traces do not fit previously formulated categorizations. Therefore, the features obtained will be presented below using a terminology largely based on the descriptions proposed in previous works (Anderson, 2011;
Bridgford, 2000; Gutiérrez Sáez and Martín Lerma, 2015; Horn, 2013; Molloy, 2011; O'Flaherty et al., 2011; Soriano-Llopis and GutiérrezSáez, 2009) but with few adaptations and additions.

When blades collided, the metal of the edges yielded producing mainly notches and/or dents. The depth of the notches is usually greater than their width. They can present either a ' $V$ ' or a ' $U$ ' shaped bottom and have either a vertical or curved outline (Fig. 4). Dents are plastic damage similar to notches but more rounded and shallow. They can either have a symmetrical or asymmetrical profile (Fig. 5A-C).

The displacement of material under impact can also generate thickening in the immediate surroundings of the damage (Fig. 4A and 


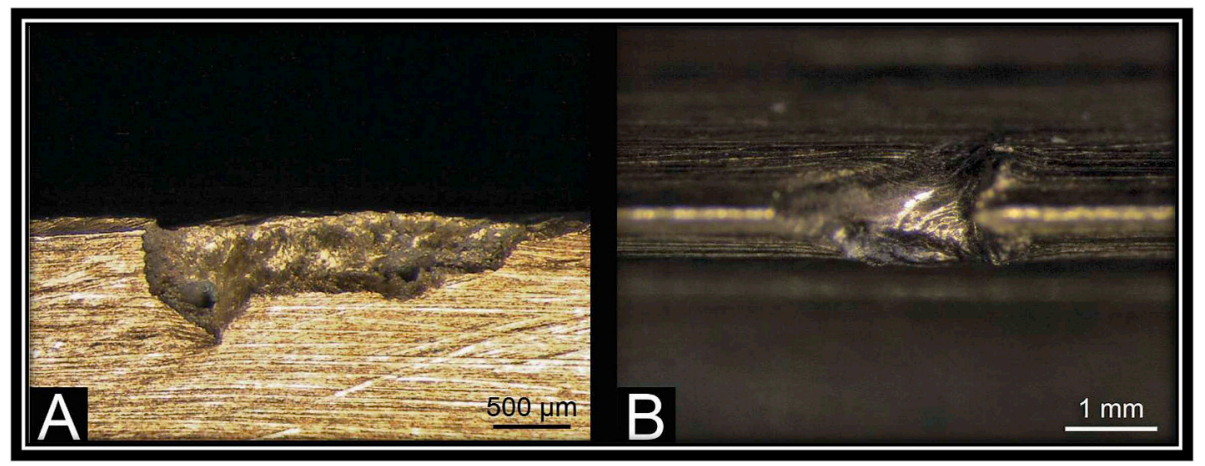

Fig. 7. Examples of traces obtained experimentally. (A) Structural failure, 'gas-voids' visible; (B) grooves inside an asymmetrical dent.

5A). In the cases in which the impact-stress surpasses the ultimate strength of the material, fissuring and breakage might occur (Fig. 5C). If blades meet with power or under an angle small enough, one edge can slide over the other in a manner similar to skipping stones on a lake's surface, producing rippling traces (Fig. 5D). Similarly, one blade might also briefly slice into the other, chipping off the superficial part of its edge (Fig. 5E) or push down a brief portion of the edge generating bowing (Fig. 5F).

In case of edge-vs-flat collisions, the edge deforms plastically under the strain of the impact and gets displaced along its horizontal axis, producing flattening (Fig. 6A and B). Conversely, the sword-flat can display blow marks (Fig. 6C). A single action can produce more than one of these marks, but they would always maintain the same orientation. In case a sword's edge hits -and successively drags-on the opponent's flat, but close to the edge, grazing damage can take place (Fig. 6D). Furthermore, sometimes a sword hit on the flat by an opponent's blade might bend at an angle of roughly $10-20^{\circ}$ from its longitudinal axis towards the side that received the blow (Fig. 6E).

Finally, if the metal is hit in a spot whose structural integrity is compromised by crafting flaws, the redistribution of the stress induced by the collision might be altered. This was observed during the tests when, after impact, a portion of a replica's edge broke off due to structural failure, as evidenced by 'gas-voids' visible in the inside of feature produced (Fig. 7A). These are interpretable as gas-bubbles encapsulated in the sword during the casting process.

\subsection{Micro-dynamics of blade impacts}

Most of the time, it is possible to identify the angle of impact between the two swords by tracing the bisecting line of the angle created by the encounter of the two lines extending from the feature's sides (cf. Horn, 2013, 22). For broader and shallower traces, however, such reconstruction is less unequivocal. Occasionally, it is possible to reconstruct the directionality of the blow from the grooves left inside the feature (Fig. 7B).

In some tests, swords have been observed to be slightly 'rocking' after colliding. This reconstruction is also supported by the occasional presence of trails (Fig. 8A), which signal a moment in which the impacting edge grazed the side of the other blade while deforming its edge. Sometimes, the blades might also briefly twist within the damage feature created. Such a movement, besides enlarging the damage feature, can generate burrs: adjacent portions of edge which are displaced after the cut and protrude on the side with a curl (Fig. 8B-D; see also 4C, $5 \mathrm{E})$. One specific notch is particularly illustrative of these dynamics: this feature shows an evident groove on the inside, signaling the orientation of the entering blade, and a burr and a trail with opposite orientations produced by the blade on its way out (Fig. 8C and D).
While the interior of some damage-features appears relatively smooth from top-view (with the exception of occasional grooves), some show an uneven surface, consisting of two parts gently declining outwards separated in the middle by a more elevated band roughly where the edge formally was. Such an 'hourglass-shaped' feature could possibly be explained as the result of rocking blades as well: with the 'neck' of the feature formed after the primary impact (where the swords firstly stopped cutting into each other), and the opposing wider parts constituted by the material displaced during secondary movements (Fig. 8E and F).

\subsection{Connecting traces to gesture}

Notches and dents are the most common combat features obtained in the edge-vs-edge scenarios, forming on both the attacking and defending swords. Moreover, in more than one case, the same scenario has produced both kinds of traces (Table 2). Nevertheless, if considered together, a degree of uniformity can be appreciated observing the consistency of the results from similar actions, as exemplified by the extra repetition of the hard block vs thrusting scenario (cf. Table 2, scenario 4 and scenario 8). Despite the large overlap in the genesis of notches and dents, some sub-trends indicate a relation between movements and trace formation. Notches seem to occur more frequently in hard block scenarios, while dents, especially the asymmetrical ones, appear more often as a result of deflections (Table 2). Furthermore, curved/diagonal notches have been generated exclusively when swords collided violently, as a consequence of a hard block against a diagonal or a thrusting attack, while no dent was formed. Said combinations also generally resulted in deeper notches (in some cases deeper than $3 \mathrm{~mm}$ ) than those originating from any other scenario (c. 1/1,5 mm deep).

A rippling feature was generated only once as the result of a direct collision. However, similar features (two specimens) originated as secondary impacts (as a product of the edges 'bouncing') on a defending sword during scenario 1 . A quantitative difference exists between primary and secondary rippling features, with the former affecting a portion of the edge of roughly $5 \mathrm{~mm}$ and the latter not exceeding $2 \mathrm{~mm}$ in length. Chipping, and bowing originated exclusively from secondary impacts (Table 2).

A significantly high degree of uniformity characterizes the traces produced by edge-against-flat collisions. Flattening damage occurred on the attacking sword in all the occasions in which contact with the flat was tested. Flat-deflections against slashing attacks (scenario 7; Table 2) produced grazing on the defending sword. The same kind of trace has also been observed forming after one of the collisions in scenario 5 (Table 2): one fighter reported to have twisted the wrist 'a little too much' while defending, partially deflecting the blow with the flat of his sword instead of the edge. Bending of the sword took place 


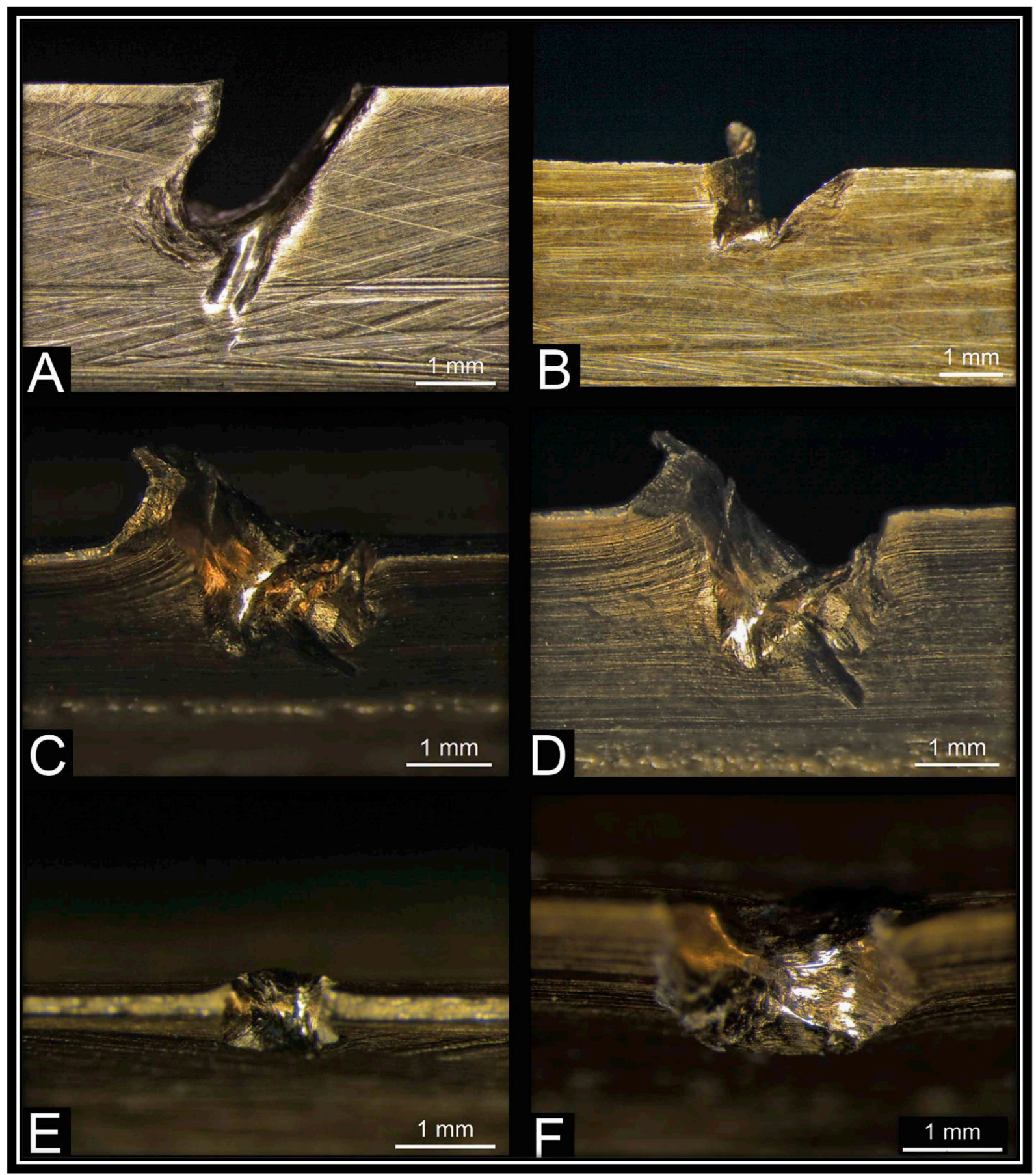

Fig. 8. Examples of traces obtained experimentally. (A) Curved notch with thickening (bottom-left) and trails (bottom-right); (B) curved notch with evident burr (left); (C) groove inside a notch (top view); (D) another perspective of the same notch, with burr visible on the top-left and trail at the bottom-right; (E, F) examples of 'hourglass feature' (top view).

once while testing a hard block and once while testing a deflection, while in two other repetitions the defending sword stayed unbent (Table 2). In one case bending caused fissuring on the side of the sword opposite to the one receiving the blow, suggesting that this kind of collision could jeopardize the integrity of the weapon.

No other scenario produced bending, including the hard blocks against thrusting attacks, which -according to the fighters- was the most plausible candidate for inducing such a damage (see section 3, and Table 2). This is at odds with other combat experiments which reported cases of bending at almost every exchange (Crellin et al., 2018, 295). Finally, it must be noted that, in one case, after a hard block with the flat, the defending sword displayed no sign of damage. This also constitutes the only case in which a sword registered no visible damage after an impact (scenario 3, Table 2). 
Table 3

Details on the archaeological swords discussed in this paper. 'Traces' refers to the total amount of combat-compatible traces detected on each item.

\begin{tabular}{|c|c|c|c|c|}
\hline Museum ID & Type & Preservation & Traces & References \\
\hline e1981/1.10 & Ewart Park & $\begin{array}{l}\text { Almost complete (small portion of the hilt missing), scarce } \\
\text { corrosion, patina chemically removed. }\end{array}$ & 7 & Cowen (1968), 449 n.6; Roymans (1991), appendix 1: n.1 \\
\hline GL 69 & Gündlingen & $\begin{array}{l}\text { Almost complete (portion of the hilt missing), edges considerably } \\
\text { corroded, dark brown patina gradually lightening towards the tip. } \\
\text { Deep striations indicating modern cleaning. }\end{array}$ & 5 & $\begin{array}{l}\text { Cowen (1968), 439: n.138; Fontijn (2002), appendix 5.5; Roymans } \\
\text { (1991), appendix 2: n.10 }\end{array}$ \\
\hline k1896/9.1 & Gündlingen & $\begin{array}{l}\text { Complete, edges mildly corroded, dark brown-grey patina. Deep } \\
\text { striations indicating modern cleaning. }\end{array}$ & 9 & $\begin{array}{l}\text { Cowen (1968), 440: n.145; Fontijn (2002), appendix 5.5; Roymans } \\
\text { (1991), appendix 2: n.4 }\end{array}$ \\
\hline e1949/5.1 & Gündlingen & $\begin{array}{l}\text { Almost complete (small portions of hilt and tip missing), edges } \\
\text { considerable corroded, dark green patina. }\end{array}$ & 4 & $\begin{array}{l}\text { Cowen (1968), 440: n.148; Fontijn (2002), appendix 5.5; Roymans } \\
\text { (1991), appendix 2: n.6 }\end{array}$ \\
\hline
\end{tabular}

\section{Archaeological comparisons}

In order to assess the applicability of our experimental framework, a 'pilot' microscopic use-wear analysis was performed on a sample of four LBA swords from the National Museum of Antiquities in Leiden (Table 3). The items were observed under the same microscope used for the analysis of the replicas (see section 3); each wear-trace was photographed from the side and from the top, and noted on a 1:1 drawing of the sword. It has to be stressed that the traces discussed in this section are presented with the sole purpose of providing examples of, and enabling the reader to assess, the potential of the investigative framework presented and do not represent the totality of the combat features detected on the swords (see Table 3, 'Traces' column). An indepth analysis of the traces of use of LBA/Early Iron Age bronze weaponry from various regions of continental Europe is currently being carried out.

Recognizing use-wear on archaeological copper-alloy items is hampered by various post-depositional modifications. Corrosion, retrieval circumstances, or curation history can alter or obliterate usetraces (Gutiérrez Sáez and Martín Lerma, 2015, 185; Horn, 2013 34-36; Horn and Holstein, 2017). The sample has been selected randomly among the LBA swords stored in the museum. They all come from river contexts (as the majority of the swords found in the Netherlands - cf. Fontijn, 2002), and they vary considerably in the degree of corrosion and curatorial treatment. Nevertheless, a number of traces analogous to those obtained experimentally have been recognized (Table 3 ).

For example, one of the swords (e1981/1.10) displays a feature similar to the curved notches produced in the experiments. Its shape is compatible with an origin from the collision with another sharp edge, and this interpretation is reinforced by the grooves visible inside the feature (Fig. 9A and B). The sword also presents marks that are comparable to flattening damage (Fig. 9C and D). Remarkably, the same sword is also bent in a fashion similar to the bending that occurred experimentally. A succession of two depressions morphologically and dimensionally comparable to the rippling traces obtained experimentally from secondary impacts have also been frequently detected on swords' edges (Fig. 9E).

Various traces analogous to asymmetrical dents have been found on the edges of the swords. At times, they were associated with potential trails (Fig. 10A, compare to 10B) or possible thickening or filed/hammered burrs (Fig. 10C), and occasionally displaying grooves plausibly generated by impacts with a sharp edge (Fig. 10D).

Finally, worthy of mention is the case of a trace resembling a dent identified on a highly corroded sword (e1949/5.1; Fig. 11A). However, considering the loss of depth caused by corrosion (roughly around
$3 \mathrm{~mm}$ ), we can compare this feature with wide, U-shaped notches (Fig. 11B). This similarity is supported also by the characteristic morphology of the interior: from a top view, a distinctive hourglass-shape feature is recognizable, as in analogous traces obtained experimentally (Fig. 11C and D).

\section{Discussion}

Our experiments have shown that combat with bronze swords produces damage at almost every collision, even after less severe impacts, which is partially at odds with what was postulated before (cf. Horn, 2013, 40). Conversely, the tests highlighted how combat might produce traces subtle in size, such as notches and dents less than $1 \mathrm{~mm}$ deep (cf. Figs. 4B and 5A-C), and others traces (e.g. rippling, bowing, grazing, and flattening) whose identification on corroded specimens might not be straightforward. It is important to take into account such occurrences when analysing archaeological items, since similar traces risk to be overlooked in a macroscopic examination, or to be easily eradicated by corrosion.

Several of the most visible traces obtained in the tests are comparable with the features obtained in previous experiments on copper-alloy weapons (cf. Anderson, 2011, Fig. 6; Crellin et al., 2018, Figs. 13.513.16; Hermann et al. in press; O'Flaherty et al., 2011, Figs. 11-12). Such an outcome further validates our results and suggests that the presence of a small quantity of lead in the alloy does not influence features formation radically. This is an encouraging outcome: if combat damage is not significantly influenced by the composition of the blades, conclusions on the use of archaeological weapons can be drawn, even in the -several- cases in which their exact chemical composition is undocumented. Nevertheless, additional controlled laboratory experiments explicitly designed to assess the relationship between combat damage and alloy composition (cf. Soriano-Llopis and Gutiérrez-Sáez, 2009) are necessary before drawing final conclusions.

For what concerns the link between trace formation and specific combat situations, the way in which defences are performed seems to constitute the most relevant variable. Hard blocks against diagonal and thrusting strikes were more likely to produce extensive and visible damage on the sword edges. On the other hand, deflections have a tendency to produce less deep and destructive features. Furthermore, our experiments show that edge-on-flat collisions generally leave different marks from those produced by edge-on-edge combinations. In contrast to the edge-on-edge combinations, edge-on-flat combinations produce different traces between the attacking and the defending sword, enabling the reconstruction of the role that the weapon had in a collision. These findings suggest that a general assessment of the 


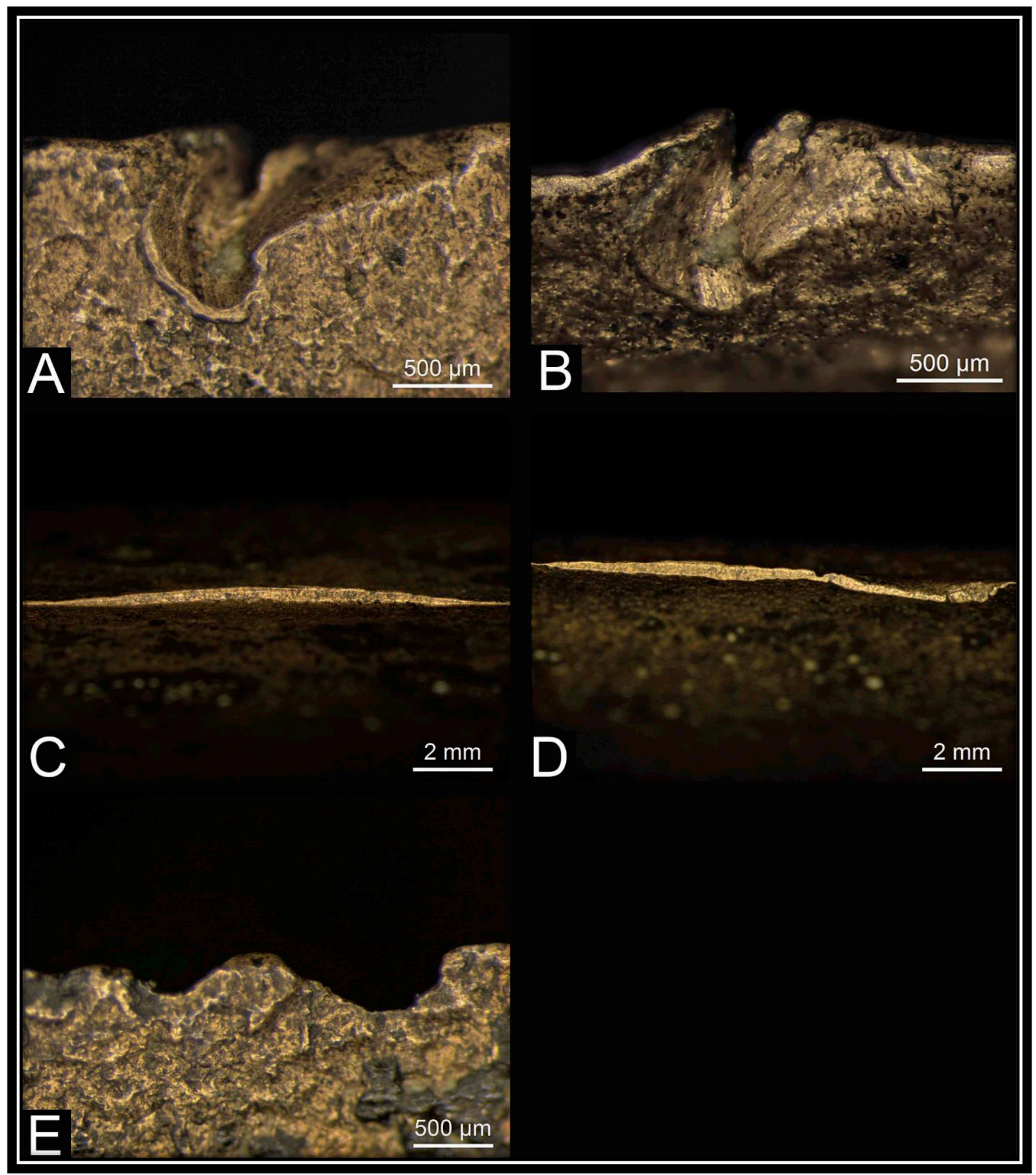

Fig. 9. Use wear on archaeological sword (e1981/1.10). (A) Possible curved notch; (B) top view of the same notch, striations visible inside; (C,D) possible flattening traces; (E) possible case of rippling.

combat techniques performed with BA swords through the analysis of the marks on the objects is indeed possible, although a larger amount of experimental trials is needed to fine-tune the associations and better assess variability. Furthermore, results demonstrate that certain ways of combat (possibly skill-dependant) might be less archaeologically visible than others and thus call for extra caution during analysis.

The detailed micro-wear analysis of the features both from side and top view, allowed a deeper understanding of the damage formation dynamics. Such knowledge has demonstrated to constitute a valid tool for the interpretation of use-wear on archaeological swords. Several combat-compatible traces, plausibly generated by hard blocks as well as by advanced deflections, have been detected on LBA swords. This occurrence speaks in favour of using basic historical fencing notions as a bio-mechanical scaffolding for the reconstruction of BA combat 


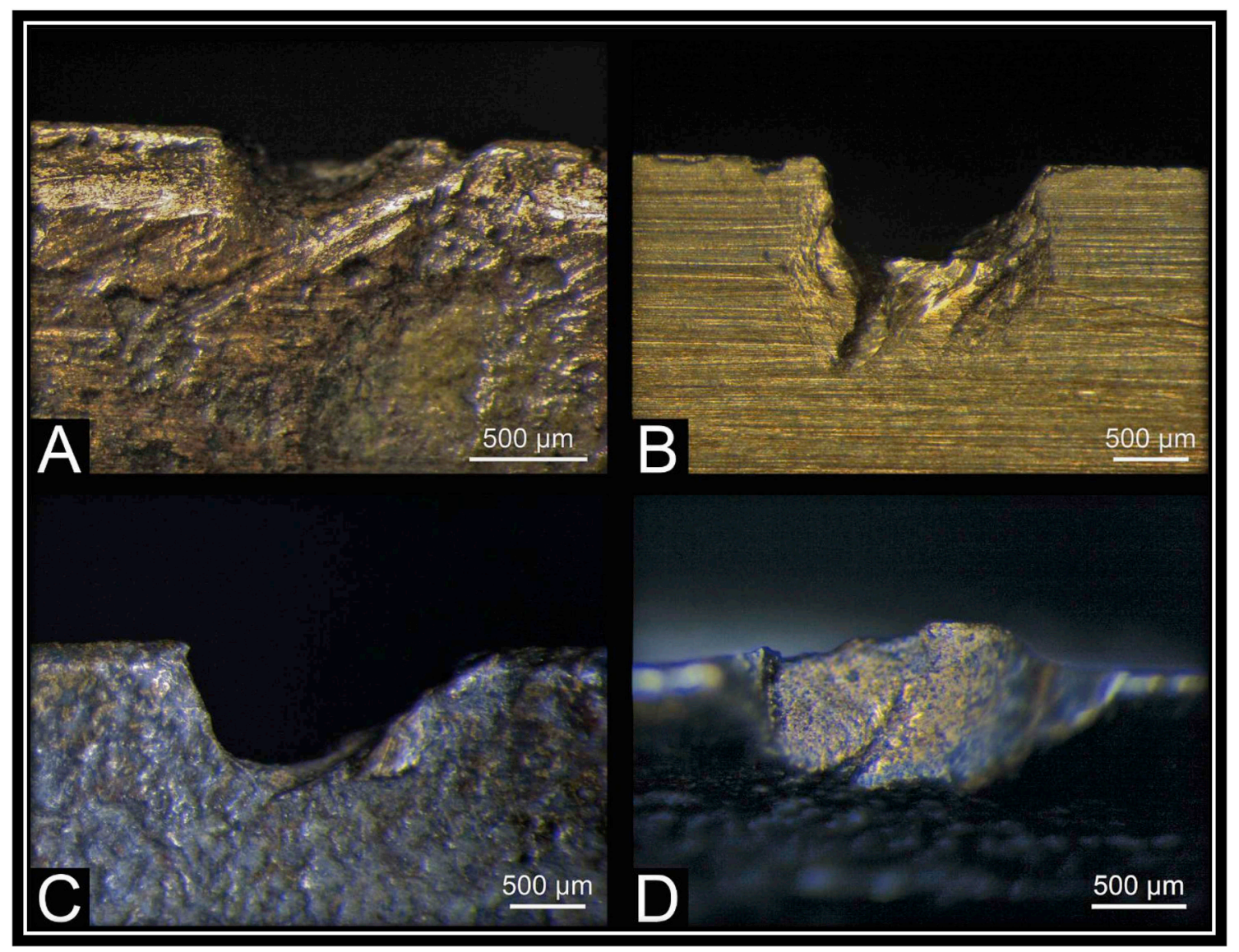

Fig. 10. (A) Possible case of asymmetrical dent with trail on archaeological sword (GL 69); (B) asymmetrical dent with trail obtained experimentally; (C) an asymmetrical dent-like feature on archaeolgical sword (k1896/9.1) bearing on the right side a possible hammered/filed burr or thickening; (D) top-view of the same dent-like feature showing a groove.

dynamics.

Although more research is needed, the relations between features and combat situations highlighted here open interesting avenues of investigation. Combat is a highly social activity: both the learning and the performance of combat actions take place within a social environment with its own tradition of notions and ways of doing things (sensu Mauss, 1973 and Wenger, 1998). If applied to large archaeological data-sets, the ability to point out patterns of specific fighting choices (e.g. different way of defending) would enable researchers to better investigate aspects of prehistoric martiality which have only recently been brought-up, such as the level of skill of combat practitioners and the existence of regional or period-specific styles or context-bound rules of fighting (e.g. Gentile et al., 2018; Horn, 2015; Molloy, 2017; Vandkilde, 2018).

\section{Conclusion}

With this paper we hope to contribute to the development of experimental archaeology and use-wear analysis applied to metalwork, and in particular to bronze weaponry. We proposed a replicable method for the experimental investigation of combat damage which balances analogy with real combat situations and a necessary control over the variables. The ability to link each combat feature produced to the correspondent combat situation allowed to effectively assess the uniformity of the results and enabled a first attempt at investigating the relation between movement executed and damage created. Furthermore, our findings were successfully implemented in a pilot study of use-wear on archaeological swords. Nevertheless, a larger number of tests is needed to evaluate more accurately the extent of the relationship between traces produced and different movements. The nature of more subtle features (e.g. bending, flattening, bowing, rippling) should be further investigated in order to rule out other possible non-combat origins. In conclusion, we hope that the knowledge produced by our work will be a helpful tool for future use-wear analyses of large sets of BA weaponry aimed at answering current questions on BA Martiality.

\section{Conflicts of interest}

The authors declare that they have no conflict of interests.

\section{Funding}

This work was supported by the Netherlands Organisation for Scientific Research (NWO) [project number: 322-60-010]. 


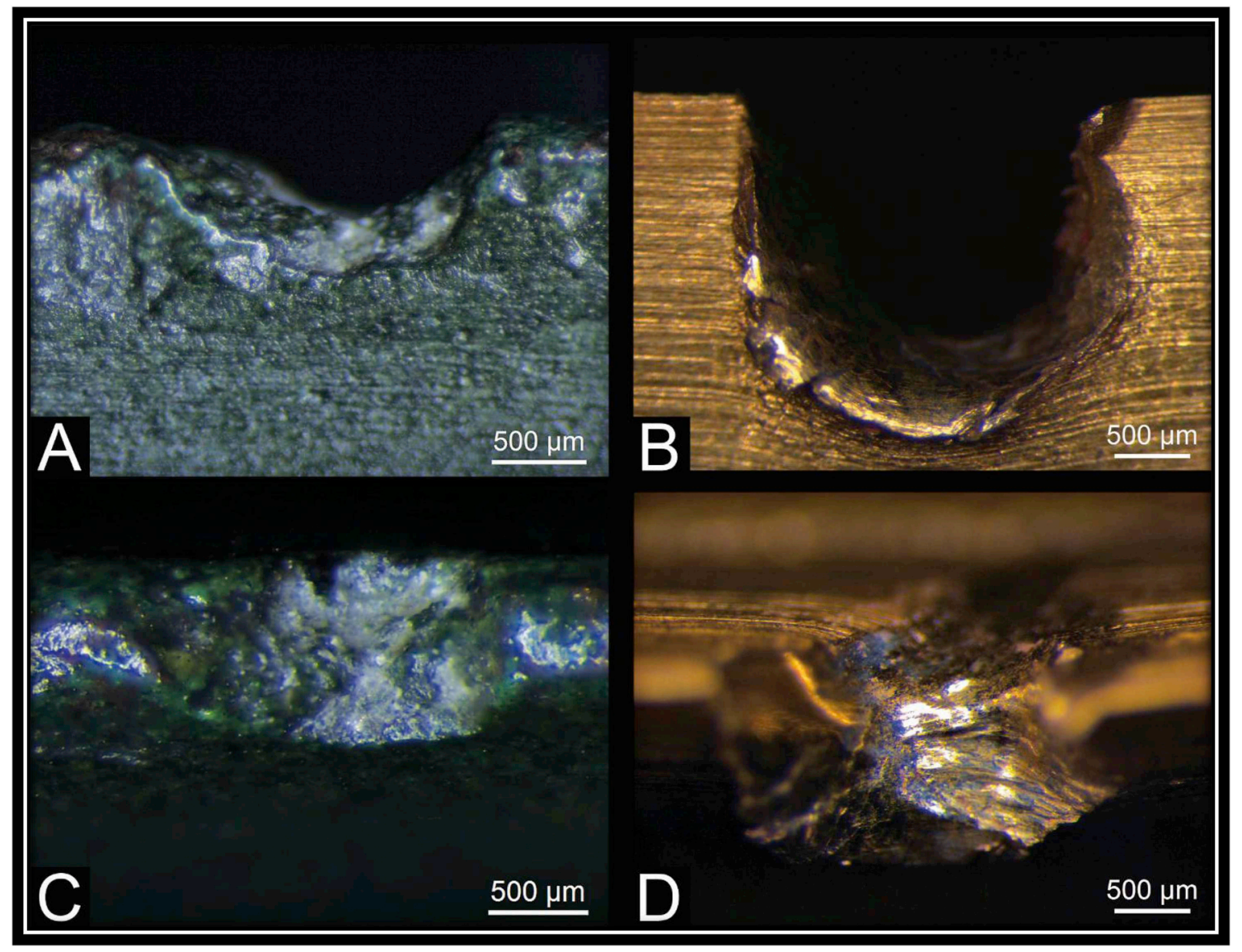

Fig. 11. (A) Possible case of U-shaped notch with hourglass feature on archaeological sword (e1949/5.1); (C, top view); (B) a U-shaped notch with hourglass feature obtained experimentally (D, top-view).

\section{Acknowledgements}

The authors would like to thank David Fontijn for inspiring this project and commenting upon an earlier version of the article. We also thank Patrick Degryse for his advice on bronze properties and Bastiaan Steffens for his editing comments. We are grateful to the editor and to the three anonymous peer reviewers for their insightful comments. We are indebted to Casper van Dijk (www.hemabond.nl), Jaap Hogendoorn (www.springlevend-verleden.com), and Jeroen Zuiderwijk (www. facebook.com/barbarianmetalworking) for their expert advice and for making the experiments possible, and to the staff of the The National Museum of Antiquities of Leiden, especially in the person of Luc Amkreutz, for allowing us to study some of the swords in the collection. Finally, we would like to thank Rachel Crellin, Andrea Dolfini, Christian Horn, and Barry Molloy for the insightful conversations on experimental archaeology and use-wear analysis applied to bronze weaponry. All opinions and errors rest with the authors.

\section{References}

Anderson, K., 2011. Slashing and thrusting with Late Bronze Age spears: analysis and experiment. Antiquity 85 (328), 599-612. https://doi.org/10.1017/ S0003598X00067983.

Arnoldussen, S., Visser, R., 2014. More than a point on a map: the leeuwarden late bronze age spearhead. In: Theunissen, L., Arnoldussen, S. (Eds.), Metaaltijden 1. Bijdragen in de studie van de metaaltijden. Sidestone Press, Leiden, pp. 97-108.

Bradley, R., 2017. A Geography of Offerings: Deposits of Valuables in the Landscapes of Ancient Europe. Oxbow Books, Oxford.

Brandherm, D., Moskal-del Hoyo, M., 2010. Las espadas en lengua de carpa - aspectos morfológicos, metalúrgicos y culturales. Trab. Prehist. 67 (2), 431-456. https://doi. org/10.3989/tp.2010.10049.

Bray, P.J., 2016. Metal, metalwork and specialisation: the chemical composition of British Bronze Age swords in context. In: Koch, J.T., Cunliffe, B. (Eds.), Celts from the West
III. Atlantic Europe in the Metal Ages - Questions of Shared Language. Oxbow books, Oxford, pp. 263-278.

Bridgford, S., 2000. Weapons, Warfare and Society in Britain 1250-750 BC. Unpublished PhD Thesis. University of Sheffield, Sheffield.

Callahan, E., 1999. What is experimental archaeology? In: Westcott, D. (Ed.), Primitive Technology: A Book of Earth Skills. Gibbs Smith, Layton, pp. 4-6.

Coffyn, A., Gomez, J., Mohen, J.-P., 1981. L'apogée du bronze atlantique: le dépôt du Vénat. Picard, Paris.

Colquhoun, I., Burgess, C., 1988. The Swords of Britain. Prähistorische Bronzefunde, IV, vol. 5 Verlag C.H. Beck, Munchen.

Cowen, J.D., 1968. The hallstatt sword of bronze: on the continent and in Britain. Proc Prehist. Soc. 33, 377-454. https://doi.org/10.1017/S0079497X00014146.

Crellin, R.J., Dolfini, A., Uckelmann, M., Hermann, R., 2018. An experimental approach to prehistoric violence and warfare. In: Dolfini, A., Crellin, R.J., Horn, C., Uckelmann, M. (Eds.), Prehistoric Warfare and Violence: Quantitative and Qualitative Approaches. Springer, Cham, pp. 279-305. https://doi.org/10.1007/978-3-31978828-9.

Dolfini, A., 2011. The function of Chalcolithic metalwork in Italy: an assessment based on use-wear analysis. J. Archaeol. Sci. 38 (5), 1037-1049. https://doi.org/10.1016/j.jas. 2010.11.025.

Dolfini, A., Crellin, R.J., 2016. Metalwork wear analysis: the loss of innocence. J. Archaeol. Sci. 66, 78-87. https://doi.org/10.1016/j.jas.2015.12.005.

Ferguson, J.R., 2010. Designing Experimental Research in Archaeology: Examining Technology through Production and Use. University Press of Colorado, Boulder.

Fontijn, D., 2002. Sacrificial Landscapes. Cultural Biographies of Person, Objects and "Natural" Places in the Bronze Age of the Southern Netherlands, C. 2300-600 BC University of Leiden, Leiden.

Fontijn, D., 2005. Giving up weapons. In: Parker Pearson, M., Thorpe, I.J.N. (Eds.), Warfare, Violence and Slavery in Prehistory, Proceeding of a Prehistoric Society Conference at Sheffield University. Archaeopress, Oxford, pp. 145-154.

Gentile, V., 2017. Martiality in Practice. An Experimental Archaeology and Use-Wear Analysis Approach to the Study of the Phenomenon of Sword Depositions in the Southern Netherlands between the Late Bronze Age and the Early Iron Age. Unpublished RMA Thesis. Leiden University, Leiden.

Gentile, V., Sparacello, V.S., D'Ercole, V., Coppa, A., 2018. Martial practices and warrior burials: humeral asymmetry and grave goods. In: Dolfini, A., Crellin, R.J., Horn, C., Uckelmann, M. (Eds.), Prehistoric Warfare and Violence: Quantitative and Qualitative Approaches. Springer, Cham, pp. 279-305. https://doi.org/10.1007/9783-319-78828-9 4.

Gerloff, S., 2004. Halstatt fascination: "Halstatt" buckets, swords and chapes from Britain 
and Ireland. In: Roche, H., Grogan, E., Bradley, J., Coles, J., Raftery, B. (Eds.), From Megaliths to Metals: Essays in Honour of George Eogan. Oxbow, Oxford, pp. 124-154.

Gutiérrez Sáez, C., Martín Lerma, I., 2015. Traceology on metal. Use-wear marks on copper-based tools and weapons. In: Marreiros, J.M., Gibaja Bao, J.F., Ferreira Bicho, N. (Eds.), Use-Wear and Residue Analysis in Archaeology. Springer, New York, pp. 171-188. https://doi.org/10.1007/978-3-319-08257-8.

Harding, A.F., 2007. Warriors and Weapons in Bronze Age Europe. Archaeolingua, Budapest.

Harrison, R.J., 2004. Symbols and Warriors : Images of the European Bronze Age. Western Academic \& Specialist Press, Bristol England.

Hermann, R., Dolfini, A., Crellin, R.J., Uckelmann, M., 2019. Researching Bronze Age swordsmanship: experiments and wear analysis. In: Deutscher, L., Kaiser, M., Wetzler, S. (Eds.), The Sword: Form and Thought. Martlesham: Boydell \& Brewer (in press).

Horn, C., 2015. Combat and change: remarks on early bronze age spears from Sweden. In: In: Suchowska-Ducke, P., Reiter, S.S., Vandkilde, H. (Eds.), Forging Identities. The Mobility of Culture in Bronze Age Europe, vol. 2. British Archaeological Reports, Oxford, pp. 201-212.

Horn, C., 2013. Weapons, fighters and combat: spears and swords in early bronze age Scandinavia. Danish J. Archaeol. 2 (1), 20-44. https://doi.org/10.1080/21662282 2013.838832 .

Horn, C., Kristiansen, K., 2018a. Warfare in Bronze Age Society. Cambridge University Press, Cambridge.

Horn, C., Kristiansen, K., 2018b. Introducing bronze age warfare. In: Horn, C. Kristiansen, K. (Eds.), Warfare in Bronze Age Society. Cambridge University Press, Cambridge, pp. 1-15. https://doi.org/10.1017/9781316884522.002.

Horn, C., von Holstein, I.C.C., 2017. Dents in our confidence: the interaction of damage and material properties in interpreting use-wear on copper-alloy weaponry. J. Archaeol. Sci. 81, 90-100. https://doi.org/10.1016/j.jas.2017.04.002.

Huth, C., 2000. Quality and quantity in late bronze and early Iron age systems. In: Giumilia-Mair, A. (Ed.), Ancient Metallurgy between Oriental Alps and Pannonia Plain. Workshop-Trieste, 29-30 October 1998. Associazione Nazionale per Aquileia, Trieste, pp. 27-39.

Jantzen, D., Brinker, U., Orschiedt, J., Heinemeier, J., Jürgen, P., Hauenstein, K., et al., 2011. A bronze age battlefield? Weapons and trauma in the Tollense Valley, northeastern Germany. Antiquity 85 (June 2011), 417-433. https://doi.org/10.1017/ S0003598X00067843.

Jung, R., Mehofer, M., 2013. Mycenaean Greece and Bronze age Italy: cooperation, trade or war? Archaol. Korresp. 43 (2), 175-193.

Kienlin, T., Ottaway, B.S., 1998. Flanged axes of the North-Alpine region: an assessment of the possibilities of use-wear analysis on metal artefacts. In: Mordant, C., Pernot, M., Rychner, V. (Eds.), L'Atelier Du Bronzier En Europe Du XXe Au VIIIe Siècle Avant Notre Ère: Du Mineral Au Métal Du Métal À L'objet. CTHS, Paris, pp. 271-286.

Kristiansen, K., 2002. The tale of the sword-swords and swordfighters in Bronze Age Europe. Oxf. J. Archaeol. 21 (4), 319-332. https://doi.org/10.1111/1468-0092. 00166.

Kristiansen, K., Larsson, T.B., 2005. The Rise of Bronze Age Society: Travels, Transmissions and Transformations. Cambridge University Press, Cambridge.

Lammers-Keijsers, Y.M.J., 2005. Scientific experiments: a possibility? Presenting a general cyclical script for experiments in archaeology. EuroREA 2, 18-24.

Lecküchner, H., Forgeng, J.L., 2015. The Art of Swordsmanship. The Boydell Press, Woodbridge.

Lidke, G., Jantzen, D., Lorenz, S., Terberger, T., 2018. The bronze age battlefield in the Tollense Valley, Northeast Germany. In: Fernández-Götz, M., Roymans, N. (Eds.), Conflict Archaeology. Materialities of Collective Violence from Prehistory to Late Antiquity. Routledge, Abingdon, pp. 61-68.

Marreiros, J., Mazzucco, N., Gibaja, J.F., Bicho, N., 2015. Macro and micro evidence from the past: the state of the art of archaeological use-wear studies. In: Use-wear and Residue Analysis in Archaeology. Springer, Cham, pp. 5-26. https://doi.org/10. 1007/978-3-319-08257-8.

Mathieu, J.R., 2002. Introduction - experimental Archaeology. Replicating past objects, behaviors and processes. In: Mathieu, J.R. (Ed.), Experimental Archaeology. Replicating Past Objects, Behaviors and Processes. Archaeopress, Oxford, pp. 1-11.

Mauss, M., 1973. Techniques of the body. Econ. Soc. 2 (1), 70-88. https://doi.org/10. $1080 / 03085147300000003$

Melheim, L., Horn, C., 2014. Tales of hoards and swordfighters in early bronze age Scandinavia: the brand new and the broken. Norweg. Archaeol. Rev. 47 (1), 18-41. https://doi.org/10.1080/00293652.2014.920907.

Molloy, B., 2007. What's the bloody point?: bronze age swordsmanship in Ireland and britain. In: Molloy, B. (Ed.), The Cutting Edge: Studies in Ancient and Medieval Combat. Tempus, Stroud, pp. 90-111.

Molloy, B., 2008. Martial arts and materiality: a combat archaeology perspective on Aegean swords of the fifteenth and fourteenth centuries BC. World Archaeol. 40 (1),
116-134. https://doi.org/10.1080/00438240701843611.

Molloy, B., 2009. For Gods or men? A reappraisal of the function of European Bronze Age shields. Antiquity 83, 1052-1064.

Molloy, B., 2010. Swords and swordsmanship in the aegean bronze age. Am. J. Archaeol. 114 (3), 403-428.

Molloy, B., 2011. Use-wear analysis and use-patterns of Bronze Age swords. In: Uckelmann, M., Mödlinger, M. (Eds.), Warfare in Bronze Age Europe: Manufacture and Use of Weaponry. Archaeopress, Oxford, pp. 67-84.

Molloy, B., 2017. Hunting warriors: the transformation of weapons, combat practices and society during the bronze age in Ireland. Eur. J. Archaeol. 20 (2), 280-316. https:// doi.org/10.1017/eaa.2016.8.

Mörtz, T., 2013. Zerteiltes Leid. Anmerkungen zur Deutung mutwilliger Beschädigungen von Metalldeponierungen der späten Bronzezeit. Mitteilungen Der Berliner Gesellschaft Für Anthropologie. Ethnologie Und Urgeschichte 34, 55-66.

Mörtz, T., 2018. Violence and ritual in late bronze age Britain: weapon depositions and their interpretation. In: Horn, C., Kristiansen, K. (Eds.), Warfare in Bronze Age Society. Cambridge University Press, pp. 168-188. https://doi.org/10.1017/ 9781316884522.012.

Northover, J.P., Bridgford, S.D., 2002. The characterisation of a bronze age weapon hoard. MRS Proceedings 712 (June 1994) II7.5. https://doi.org/10.1557/PROC-712II7.5.

O'Flaherty, R., Gilchrist, M.D., Cowie, T., 2011. Ceremonial or deadly serious? New insight into the function of Irish Early Bronze Age halberds. In: Uckelmann, M., Mödlinger, M. (Eds.), Bronze Age Warfare: Manufacture and Use of Weaponry. Archeopress, Oxford, pp. 39-52.

Osgood, R., Monks, S., Thomas, J., 2000. Bronze Age Warfare. Sutton, Stroud.

Outram, A.K., 2008. Introduction to experimental archaeology. World Archaeol. 40 (1), 1-6. https://doi.org/10.1080/00438240801889456.

Quilliec, B., 2008. Use, wear and damage: treatment of bronze swords before deposition. In: Hamon, C., Quillec, B. (Eds.), Hoards from the Neolithic to the Metal Ages in Europe: Technical and Codified Practices. Archaeopress, Oxford, pp. 67-78.

Radivojević, M., Roberts, B.W., Pernicka, E., Stos-Gale, Z., Martinón-Torres, M., Rehren, T., et al., 2018. The provenance, use, and circulation of metals in the European bronze age: the state of debate. J. Archaeol. Res. 1-55. https://doi.org/10.1007/ s10814-018-9123-9.

Roberts, B., Ottaway, B.S., 2003. The use and significance of socketed axes during the late bronze age. Eur. J. Archaeol. 6 (2), 119-140. https://doi.org/10.1177/ 146195710362002

Roymans, N., 1991. Late urnfield societies in the Northwest European plain and the expanding networks of central European hallstatt groups. In: Roymans, N., Theuws, F. (Eds.), Images of the Past: Studies on Ancient Societies in Northwestern Europe, pp. 9-89 (Amsterdam: Insitituut voor Pre- en Protohistorische Archeologie Albert Egges van Giffen).

Schenck, T., 2011. Experimenting with the unknown. In: Petersson, B., Narmo, L.E. (Eds.), Experimental Archaeology, between Enlightenment and Experience. Department of Archaeology and Ancient History, Lund University, Lund, pp. 87-98.

Soriano Llopis, I., Gutierrez Sáez, C., 2009. Use wear analysis on metal: the influence of raw material and metallurgy processes. In: 2nd International Conference. Archaeometallurgy in Europe. Associazione Italiana di Metallurgia, Milano, pp. $115-124$.

Talhoffer, H., Hergsell, G., 1998. Talhoffers Fechtbuch Gerichtliche und andere Zweikämpfe darstellend. Vs-Books, Herne.

Uckelmann, M., 2011. The function of Bronze Age shields. In: Uckelmann, M., Mödlinger, M. (Eds.), Bronze Age Warfare: Manufacture and Use of Weaponry. Archaeopress, Oxford, pp. 187-199.

Uckelmann, M., Mödlinger, M., 2011. Bronze Age Warfare : Manufacture and Use of Weaponry. Archaeopress, Oxford.

Van der Vaart-Verschoof, S., 2017. Fragmenting the Chieftain: a Practice-Based Study of Early Iron Age Hallstatt C Elite Burials in the Low Countries. SIdestone Press.

van Gijn, A., 2010. Flint in Focus: Lithic Biographies in the Neolithic and Bronze Age. Sidestone Press, Leiden.

Vandkilde, H., 2014. Breakthrough of the Nordic bronze age: transcultural warriorhood and a carpathian crossroad in the sixteenth century BC. Eur. J. Archaeol. 17 (4), 602-633. https://doi.org/10.1179/1461957114Y.0000000064.

Vandkilde, H., 2018. Body aesthetics, fraternity and warfare in the long European bronze age: postscriptum. In: Horn, C., Kristiansen, K. (Eds.), Warfare in Bronze Age Society. Cambridge University Press, pp. 229-243. https://doi.org/10.1017/9781316884522. 016.

Warmenbol, E., 1988. Broken bronzes and burned bones. The transition from bronze to Iron age in the low countries. Helinium XXVIII (2), 244-270.

Wenger, E., 1998. Communities of Practice. Cambridge University Press, Cambridge. https://doi.org/10.1017/CBO9780511803932.

York, J., 2002. The life cycle of bronze age metalwork from the thames. Oxf. J. Archaeol. 21 (1), 77-92. https://doi.org/10.1111/1468-0092.00150. 